Journal of Organometallic Chemistry, 127 (1977) 87-92

(c) Elsevier Sequoia S.A., Lausanne - Printed in The Netherlands

\title{
REACTIVE INTERMEDIATES IN THE PHOTOLYSIS OF CYCLOPENTADIENYLCOBALT(I) DICARBONYL AND IN THE REDUCTION OF CYCLOPENTADIENYLCOBALT(III) CARBONYL DIIODIDE
}

\author{
WAI-SUN LEE * and HANS H. BRINTZINGER ** \\ Department of Chemistry, The University of Michigan, Ann Arbor, Michigan 48104 (U.S.A.), \\ and Fachbereich Chemie, Universität Kanstanz, D 7750 Konstanz (West Germany)
}

(Received July 19th, 1976)

\section{Summary}

Photolysis of $\left(\mathrm{C}_{5} \mathrm{H}_{5}\right) \mathrm{Co}(\mathrm{CO})_{2}(\mathrm{I})$ in toluene or petroleum ether solution at $-78^{\circ} \mathrm{C}$ generates the unsaturated monocarbonyl species $\left(\mathrm{C}_{5} \mathrm{H}_{5}\right) \mathrm{Co}(\mathrm{CO})$, which was identified in solution by its IR spectrum. At room temperature, this monocarbonyl can associate with excess I to give $\left(\mathrm{C}_{5} \mathrm{H}_{5}\right)_{2} \mathrm{Co}_{2}(\mathrm{CO})_{3}$, or dimerize to $\left(\mathrm{C}_{5} \mathrm{H}_{5}\right)_{2} \mathrm{Co}_{2}(\mathrm{CO})_{2}$. The latter is stable as a solid, but in solution it is slowly converted to the insoluble trimer $\left(\mathrm{C}_{5} \mathrm{H}_{5}\right)_{3} \mathrm{Co}_{3}(\mathrm{CO})_{3} \cdot\left(\mathrm{C}_{5} \mathrm{H}_{5}\right)_{2} \mathrm{Co}_{2}(\mathrm{CO})_{2}$ is symmetrically cleaved by phosphines to $\left(\mathrm{C}_{5} \mathrm{H}_{5}\right) \mathrm{Co}(\mathrm{CO})\left(\mathrm{PR}_{3}\right)$, while diolefins bring about unsymmetrical cleavage to give $\left(\mathrm{C}_{5} \mathrm{H}_{5}\right) \mathrm{Co}$ (diolefin) and $\left(\mathrm{C}_{5} \mathrm{H}_{5}\right) \mathrm{Co}(\mathrm{CO})_{2}$.

\section{Introduction}

Among organometallic reactions involving coordinatively unsaturated intermediates, those of sandwich compounds with two and only two available coordination sites offer a unique opportunity to study reaction patterns and reactivity parameters. The availability in coordination compounds with a 14electron core structure of more than one coordination site for substitutions, oxidative additions, and other basic reaction steps appears to be associated with a variety of reactions relevant to homogeneous catalysis. At the same time, however, structural degrees of freedom are limited by the fairly rigid sandwich skeleton, so that reasonably accurate descriptions of the transition states may be possible. A striking example of such a 14-electron coordination core structure is that of bis(cyclopentadienyl)titanium(II), for which a wide variety of modes

\footnotetext{
* Present address at Department of Chemistry, The University of Westem Ontario, London, Canada.

* To whom correspondence should be addresced at Universität Konstanz, 7750 Konstanz, B.R.D.
} 
of reaction and their synthetic and catalytic applications have been reported [1]. The later transition metals, particularly those of Group VIII could yield comparable 14-electron core structures with two available coordination sites only in half-sandwich arrangements. One such 14-electron half-sandwich core which contains its metal in a low, yet reasonably stable, oxidation state is that of cyclopentadienylcobalt(I) and its homologues. In accord with this unique position, the coordination chemistry of cyclopentadienylcobalt(I) is comparable to that of bis(cyclopentadienyl)titanium(II) [2]. The dicarbonyl complex $\mathrm{I},\left(\mathrm{C}_{5} \mathrm{H}_{5}\right) \mathrm{Co}(\mathrm{CO})_{2}$, for example, is susceptible to photolysis; upon irradiation a trinuclear complex $\mathrm{II},\left(\mathrm{C}_{5} \mathrm{H}_{5}\right)_{3} \mathrm{Co}_{3}(\mathrm{CO})_{3}$ has been obtained [3]. A diversity of products ärise from thermal and photochemical reactions of the dicarbonyl I with substituted acetylenes [4-6]; this indicates the generation from I of coordinatively unsaturated intermediates e.g. in the photolytic reaction I $\rightarrow$ II. Vollhardt et al. [7] recently investigated the nature of these intermediates. We report further observations concerning the identity and mutual conversion pathways of reactive intermediates in these systems.

\section{Results}

\section{Low temperature photolysis of $\left(\mathrm{C}_{5} \mathrm{H}_{5}\right) \mathrm{Co}(\mathrm{CO})_{2}$}

When toluene solutions of $\left(\mathrm{C}_{5} \mathrm{H}_{5}\right) \mathrm{Co}(\mathrm{CO})_{2}$ are irradiated at $-78^{\circ} \mathrm{C}$ with $\mathrm{UV}$ light, while being continuously swept by a slow stream of $\mathrm{N}_{2}$, the IR spectra of the solutions change as follows. The initial dicarbonyl complex I exhibits two adsorptions of nearly identical intensity in its IR spectrum at 2020 and 1955 $\mathrm{cm}^{-1}$. The band at $2020 \mathrm{~cm}^{-1}$ decreases in intensity upon irradiation. In dilute solutions, after an irradiation time of about $10 \mathrm{~h}$, a species with only one carbonyl absorption at $1955 \mathrm{~cm}^{-1}$ is observed. We assign this absorption to the unsaturated monocarbonyl complex $\left(\mathrm{C}_{5} \mathrm{H}_{5}\right) \mathrm{Co}(\mathrm{CO})$ (III). Addition of triphenylphosphine to these solutions converts this species quantitatively to the known carbonylphosphine complex $\left(\mathrm{C}_{5} \mathrm{H}_{5}\right) \mathrm{Co}(\mathrm{CO})\left[\mathrm{P}\left(\mathrm{C}_{6} \mathrm{H}_{5}\right)_{3}\right]$ with $\nu(\mathrm{CO}) 1905 \mathrm{~cm}^{-1}$ [8]. Due to its instability, the monocarbonyl III cannot be isolated. At room temperature, its IR spectrum disappears, and, a new IR band in the $\mu$-CO region appears at $1785 \mathrm{~cm}^{-1}$. In more concentrated solutions, this conversion to some bridged carbonyl complex takes place even at $-78^{\circ} \mathrm{C}$. A dinuclear dicarbonyl compound can be obtained in low yield by irradiation of $I$ at $-78^{\circ} \mathrm{C}$, removal of solvent at room temperature and subsequent sublimation at $40^{\circ} \mathrm{C}$ and $10^{-3}$ Torr. This green material, which shows a single $C O$ absorption at $1798 \mathrm{~cm}^{-1}$ in petroleum ether, is identified, on the basis of its IR, NMR and mass spectra, as the dinuclear dicarbonyl IV, $\left(\mathrm{C}_{5} \mathrm{H}_{5}\right)_{2} \mathrm{Co}_{2}(\mu-\mathrm{CO})_{2} *$.

In addition, other species are observed in irradiated solutions, especially at higher concentrations of starting material $I$ in particular, the trinuclear carbonyl II, identified by its IR absorptions at 1830,1770 and $1670 \mathrm{~cm}^{-1}$. This compound is isolated. following earlier accounts [3], when the residue obtained after irradiation, removal of solvent at room temperature and sublimation, is extracted with diethyl ether.

\footnotetext{
- The anion $\left(\mathrm{C}_{5} \mathrm{H}_{5}\right) \mathrm{Co}_{2}\left(\mu-\mathrm{CO}_{2}{ }_{2}^{-}\right.$has recently been found to form when $\left(\mathrm{C}_{5} \mathrm{H}_{5}\right) \mathrm{Co}(\mathrm{CO})_{2}$ is reduced e.g with scidim amalgam [9]; IR and NMR absorptions assionable tu IV have also been observed by Vollhardt et al. [7].
} 
Recently, Vollhardt et al. have investigated related reaction systems and observed the intermediate formation of a dinuclear tricarbonyl $\mathrm{V},\left(\mathrm{C}_{5} \mathrm{H}_{5}\right)_{2} \mathrm{Co}_{2}(\mathrm{CO})_{3}$ [7]. This compound is characterized by IR absorptions at 1965 and $1814 \mathrm{~cm}^{-1}$ in Nujol. The intermediacy of this species $V$ in the consecutive photo- and dark reaction steps leading to compounds IV and II is clearly observable in highboiling petroleum ether as a solvent. Here, irradiation at $-78^{\circ} \mathrm{C}$ produces this species $V$ with an absorption at $1810 \mathrm{~cm}^{-1}$, observable at room temperature immediately after removal from the low-temperature reaction mixture. In addition, the terminal $\mathrm{CO}$ band at $2025 \mathrm{~cm}^{-1}$ decreases relative to that at $1970 \mathrm{~cm}^{-1}$. The residual absorption at $1970 \mathrm{~cm}^{-1}$ must be due, at least in part, to the terminal CO-band of the tricarbonyl V; we cannot say whether some monocarbonyl III contributes to this absorption.

A subsequent dark reaction then occurs at room temperature: the band at $1810 \mathrm{~cm}^{-1}$ associated with the dinuclear tricarbonyl $\mathrm{V}$, decreases to about half its initial intensity with an initial half-life of about $1 \mathrm{~h}$. At the same rate, a new band grows in at $1798 \mathrm{~cm}^{-1}$, indicating the formation of dinuclear dicarbonyl IV. This change is accompanied by an increase of the terminal $\mathrm{CO}$ absorption at $2025 \mathrm{~cm}^{-1}$, i.e. by regeneration of starting material 1 . When the two bands at 1810 and $1798 \mathrm{~cm}^{-1}$, associated with the dinuclear tri- and di-carbonyl complexes, respectively, have reached comparable intens ties, both remain fairly stationary, decaying synchronously with a half-life of several hours, while a band at $1762 \mathrm{~cm}^{-1}$, probably due to trimer II, continues to grow. Essentially in accord with Vollhardt et al. [7], we interpret these oibservations according to Scheme 1. The primary photoproduct III, $\left(\mathrm{C}_{5} \mathrm{H}_{5}\right) \mathrm{Co}(\mathrm{CO})$, associates with excess SCFENE 1

Generation and interconversion pathways for coordinatively unsaturated cy clopentadienylcobalt( $(0)$ carbonyl intermediates. Photochemical reaction steps are indicated by wavy arrows, thermal reactions by straight arrows: numbers in parentheses are carbonyl frequencies in $\mathrm{cm}^{-1}$.

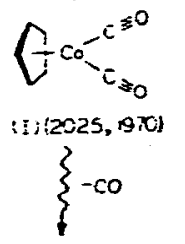

$$
A c_{i}^{i}-c \equiv 0
$$

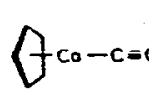

(III) 1970
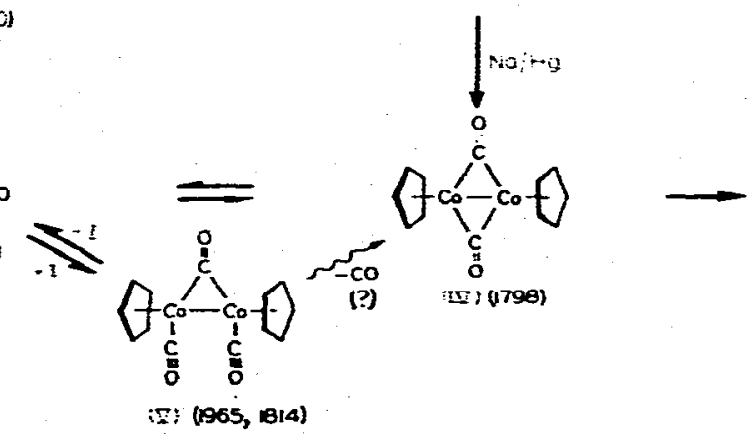

$\mathrm{Cp}_{3} \mathrm{Co}_{3} \mathrm{FOO}_{3}$

(2) $(1670,1760)$

i: $(1965,1814)$

$I$ in a concentration-dependent equilibrium to form the dinuclear tricarbonyl $\mathrm{V}$. This species can then be converted, presumably via the monocarbonyl III in equilibrium with it and I, to the dinuclear dicarbonyl IV with regeneration of starting material I. Probably V is also convertible to IV by direct photolysis under loss of $\mathrm{CO}$. The coordinatively unsaturated dicarbonyl IV can then associate with an additional monocarbonyl unit to form the trinuclear particle II, which appears 
to be the final product under our conditions.

When solutions containing a mixture of the photolysis products III, IV, V and II are exposed to carbon monoxide, complete conversion to the initial dicarbonyl $I$ is observed. Addition of triphenylphosphine to IV, $V$ or II leads to formation of the known mixed carbonylphosphine $\left(\mathrm{C}_{5} \mathrm{H}_{5}\right) \mathrm{Co}(\mathrm{CO})\left[\mathrm{P}\left(\mathrm{C}_{6} \mathrm{H}_{5}\right)_{3}\right]$ [8]. These reactions indicate the possibility of a symmetrical cleavage of the di- and tri-nuclear species by ligand attack.

The dinuclear dicarbonyl IV appears to undergo unsymmetrical cleavage as well. In its mass spectrum the ions $\left(\mathrm{C}_{5} \mathrm{H}_{5}\right) \mathrm{Co}(\mathrm{CO})_{2}{ }^{+}$and $\left(\mathrm{C}_{5} \mathrm{H}_{5}\right) \mathrm{Co}^{+}$are observed with higher yields than the symmetrical cleavage product $\left(\mathrm{C}_{5} \mathrm{H}_{5}\right) \mathrm{Co}(\mathrm{CO})^{+}$. This tendency toward unsymmetrical cleavage is also manifested in substitution reactions in solution. Thus when a solution of IV in toluene is treated with a diolefin, the corresponding diolefin complex [10] $\left(\mathrm{C}_{5} \mathrm{H}_{5}\right) \mathrm{Co}$ (diene), is formed together with an approximately equal yield of dicarbonyl I. Apparently, the difunctionality of the attacking ligand directs this substitution toward unsymmetrical cleavage of the dimer, in contrast to the symmetrical reaction mode preferred for cleavage by the monofunctional phosphine ligand.

\section{Reduction of $\left(\mathrm{C}_{5} \mathrm{H}_{5}\right) \mathrm{Co}(\mathrm{CO}) \mathrm{I}_{2}$}

In order to further establish the intermediacy of the reactive species we have investigated additional modes of obtaining these intermediates. From related studies on reactive titanium and molybdenum compounds $[1,11]$, it is known that reduction of dihalide compounds by a strongly reducing metal can lead to reactive intermediates. Reduction of the cobalt(III) diiodocarbonyl, $\left(\mathrm{C}_{s} \mathrm{H}_{5}\right) \mathrm{Co}$ $(\mathrm{CO}) \mathrm{I}_{2}[8]$, in a toluene solution at room temperature with sodium amalgam yielded a mixture of the dinuclear dicarbonyl IV, and the trinuclear carbonyl II. This establishes an independent, chemical entry into the series of intermediates represented in Scheme 1.

\section{Discussion}

The generation of coordinatively unsaturated monocarbonyl III and its interconversion reactions involving the binuclear adducts IV and $\mathrm{V}$ are undoubtedly the primary steps in a number of photochemical and thermal reactions between the dicarbonyl compound I and other, reactive ligand molecules. Applications of this basic reaction pattern toward reactions systems involving various acetylene derivatives will be discussed in a subsequent paper [12].

Concerning the stability of the binuclear dicarbonyl IV, some comparisons with related compounds are warranted. Among the comparable cyclopentadienylrhodium complexes, the only known stable dinuclear carbonyl derivative has the composition $\left(\mathrm{C}_{5} \mathrm{H}_{5}\right)_{2} \mathrm{Rh}_{2}(\mathrm{CO})_{3}$ [13], whereas the dinuclear cobalt carbonyls $\left(\mathrm{C}_{5} \mathrm{H}_{5}\right)_{2} \mathrm{Co}_{2}(\mathrm{CO})_{2}$ (IV) and $\left(\mathrm{C}_{5} \mathrm{H}_{5}\right)_{2} \mathrm{Co}_{2}(\mathrm{CO})_{3}(\mathrm{~V})$ appear to exist in equilibrium with each other and with $I$. This difference might be related to increased steric crowding around the cobalt atom as compared to rhodium, which would favor smaller coordination numbers for the $\left(\mathrm{C}_{5} \mathrm{H}_{5}\right)$ Co unit.

Formally, a cobalt-cobalt double bond has to be postulated for the dinuclear dicarbonyl IV in order to arrive ai an 18-electron valance shell configuration. For the dinuclear iron-nitrosyl compound $\left(\mathrm{C}_{5} \mathrm{H}_{5}\right)_{2} \mathrm{Fe}_{2}(\mathrm{NO})_{2}$ a comparatively 
short $\mathrm{Fe}-\mathrm{Fe}$ distance of $2.33 \AA$ in a coplanar $\mathrm{Fe}_{2}(\mu-\mathrm{NO})_{2}$ ring has been observed by Calderon et al. [14]; this was interpreted as arising from a 4-electron bond between the two metal centers. The occurrence of only one stretching mode in the IR spectrum of the isoelectronic dicarbonyl $\left(\mathrm{C}_{5} \mathrm{H}_{5}\right)_{2} \mathrm{Co}_{2}(\mu-\mathrm{CO})_{2}$ indicates a similar, coplanar geometry of the central $\mathrm{Co}_{2}(\mu-\mathrm{CO})_{2}$ ring, and hence would be compatible with an analogous bonding situation in these two isoelectronic compounds.

\section{Experimental}

General techniques and chemicals

All manipulations of air-sensitive compounds were carried out under an inert gas using either Schlenk or high-vacuum manifold techniques.

The preparations of $\left(\mathrm{C}_{5} \mathrm{H}_{5}\right) \mathrm{Co}(\mathrm{CO})_{2},\left(\mathrm{C}_{5} \mathrm{H}_{5}\right) \mathrm{Co}(\mathrm{CO}) \mathrm{I}_{2}$ and $\left(\mathrm{C}_{5} \mathrm{H}_{5}\right)_{2} \mathrm{Co}_{2} \mathrm{I}_{4}$ were based on the procedures described in ref. 3 and 8 . All solvents used for this work were doubly distilled and ciried with butyllithium or methyllithium.

\section{Instruments}

IR spectra were taken on a Shimadzu 400 spectrophotometer, proton magnetic resonance measurements with a JEOL-MH-100 high resolution spectrometer, and mass spectra on a Varian $\mathrm{CH} 7$ mass spectrometer.

\section{Photochemical preparation of $\left(\mathrm{C}_{5} \mathrm{H}_{5}\right)_{2} \mathrm{Co}_{2}(\mu-\mathrm{CO})_{2}(\mathrm{IV})$ and $\left(\mathrm{C}_{5} \mathrm{H}_{5}\right)_{3} \mathrm{Co}_{3}(\mathrm{CO})_{3}$} (II)

A solution of $0.7 \mathrm{ml}(5.44 \mathrm{mmol})$ of $\left(\mathrm{C}_{5} \mathrm{H}_{5}\right) \mathrm{Co}(\mathrm{CO})_{2}$ in $200 \mathrm{ml}$ of toluene was irradiated at dry ice temperature with a $125 \mathrm{WV}$ mercury lamp. Nitrogen was slowly bubbled through the solution during photolysis and IR spectra of the irradiated solution were recorded occasionally. After $15 \mathrm{~h}$, the irradiation was discontinued. After removal of solvent, a green solid was sublimed at $40^{\circ} \mathrm{C}$ under high vacuum from the residue. This material was identified as $\left(\mathrm{C}_{5} \mathrm{H}_{5}\right)_{2} \mathrm{Co}_{2}(\mu-\mathrm{CO})_{2}$ (IV): Its IR spectrum in Nujol exhibits a strong, broad peak at $1765 \mathrm{~cm}^{-1}$. Its proton NMR spectrum in toluene-d8 shows a sharp singlet at $\tau$ 5.61. Its molecular weight was determined as 304 by mass spectrometry (main fragment ions discussed above).

The crude black sublimation residue was extracted with diethyl ether in a Soxhlet extractor. This process was completed in half a day. The dark, partly crystalline extracts were then cooled in a $-78^{\circ} \mathrm{C}$ bath, the solvent syringed off, and the black crystals dried in vacuum. The identity of the crystals as $\left(\mathrm{C}_{5} \mathrm{H}_{5}\right)_{3}$ $\mathrm{Co}_{3}(\mathrm{CO})_{3}$ (II) was confirmed by comparison of the IR spectrum with that given by King [3]. Yield: $\left(\mathrm{C}_{5} \mathrm{H}_{5}\right)_{2} \mathrm{Co}_{2}(\mu-\mathrm{CO})_{2}(\mathrm{~V}), 0.16 \mathrm{mmol}(6.0 \%) ;\left(\mathrm{C}_{5} \mathrm{H}_{5}\right)_{3} \mathrm{Co}_{3}(\mathrm{CO})_{3}$ (II), $1.01 \mathrm{mmol}(55.6 \%)$.

\section{Reduction of $\left(\mathrm{C}_{5} \mathrm{H}_{5}\right) \mathrm{Co}\left(\mathrm{CO}_{2}\right)_{2}$, by sodium amalgam}

A toluene solution $(50 \mathrm{ml})$ of $\left(\mathrm{C}_{5} \mathrm{H}_{5}\right) \mathrm{Co}(\mathrm{CO}) \mathrm{I}_{2},(1.60 \mathrm{~g}, 3.94 \mathrm{mmol})$ was stirred with 9 mmol of sodium amalgam. After $15 \mathrm{~min}$, the purple solution changed to brown. Stirring was continued overnight. Filtration of the mixture gave a dark brown solution. The solvent and $\left(\mathrm{C}_{5} \mathrm{H}_{5}\right) \mathrm{Co}(\mathrm{CO})_{2}$ produced from the reaction 
were removed by vacuum distillation. A green solid was sublimed from the residue and identified as $\left(\mathrm{C}_{5} \mathrm{H}_{5}\right)_{2} \mathrm{Co}_{2}(\mu-\mathrm{CO})_{2}$ (IV) by comparing its IR and mass spectra to thrat obtained in section.1.

The black residue was extracted with diethyl ether in a Soxhlet extractor. The black solid obtained was identified as $\left(\mathrm{C}_{5} \mathrm{H}_{5}\right)_{3} \mathrm{Co}_{3}(\mathrm{CO})_{3}$ (II), by comparison of its IR spectrum with that given by $\mathrm{King}$ [3]. Yield: $\left(\mathrm{C}_{5} \mathrm{H}_{5}\right) \mathrm{Co}(\mathrm{CO})_{2}$ (I) 0.67 $\mathrm{mmol}(17.0 \%) ;\left(\mathrm{C}_{5} \mathrm{H}_{5}\right)_{2} \mathrm{Co}_{2}(\mu-\mathrm{CO})_{2}$ (IV), $0.13 \mathrm{mmol}(6.6 \%) ;\left(\mathrm{C}_{5} \mathrm{H}_{5}\right)_{3} \mathrm{Co}_{3}(\mathrm{CO})_{3}$ (II), $0.75 \mathrm{mmol}(56.7 \%)$.

\section{IR observations of intermediates in solution}

Photolysis of the dicarbonyl I was carried out at $-30^{\circ} \mathrm{C}$ in toluene or petroleum ether solution in a low-temperature IR cell by irradiation with a focussed UV beam derived from a $250 \mathrm{~W}$ high-pressure Xenon lamp (Hanovia). IR spectra of the irradiated solutions were recorded at various intervals at $-30^{\circ} \mathrm{C}$. Subsequently the temperature was raised to $25^{\circ} \mathrm{C}$, where the decay of the IR band at $1955 \mathrm{~cm}^{-1}$ assigned to the monocarbonyl III, and of the spectra of V and IV was followed over several hours. Similar observations were made when solutions irradiated at $-78^{\circ} \mathrm{C}$ in the synthetic irradiation vessel (section 1) were transferred to a normal solution IR cell, where their spectra were recorded at room temperature for $2-3 \mathrm{~h}$.

\section{Acknowledgements}

This work has been supported by grants from the National Science Foundation (GP 33130X), from Deutsche Forschungsgemeinschaft and from fonds der Chemischen Industrie. We are greateful to Drs. Vollhardt, Bercaw and Bergman for making available their results on the formation of $\left(\mathrm{C}_{5} \mathrm{H}_{5}\right)_{2} \mathrm{Co}_{2}(\mathrm{CO})_{3}$ in related reaction systems prior to publication.

\section{References}

1 J.E. Bercaw, R.H. Marvich, L.G. Bell and H.H. Brintzinger, J. Amer. Chem. Soc., 94 (1972) $1219:$ and literature cited therein.

2 M.D. Rausch. Pure Appl. Chem., 30 (1972) 523.

3 R.B. King. Inors. Chem. 5 (1966) 2227.

4 R. Markby. FLW. Stermberg and I. Wender. Chem Ind.. (1959) 1381.

5 R.S. Dickson and G. Wilkinson. J. Chem. Soc., (1964) 2699.

6 M.D. Rausch and R.A. Genetti, J. Org. Chem., 35 (1970) 3888.

7 K.P.C. Vollhardt, J.E. Bercaw and R.G. Bergman, J. Organometal. Chem.. 97 (1975) 283.

8 R.B. King. Inorg. Chem.. 5 (1966) 82.

9 C.S. Ilend2. N.E Shore and R.G. Bergman, J. Amer, Chem. Soc. 98 (1976) 255.

10 R.B. King. P.M. Treichel and F.G.A. Stone, J. Amer. Chem. Soc., 83 (1961) 3593.

11 J.L. Thomas and H.H. Brintzinger, J. Amer. Chem. Soc., 94 (1972) 1386;J.L. Thomas, J. Amer. Chem. Soc., 95 (1973) 1838.

12 W.S. Lee and H.H. Brintzinger, submitted for publication.

13 O.S. Mills and J.P. Nice, J. Orzanometal. Chem., 10 (1967) 337.

14 J.L. Calderon. S. Fontana. E. Frauendorfer. V.W. Day and S.D.A. Iske. J. Organometal. Chem., 64 (1974) Ci6. 